\title{
The role of feedback in the teaching-learning process
}

Delia Muste 


\title{
The role of feedback in the teaching-learning process
}

\author{
Delia Muste ${ }^{a^{*}}$ \\ ${ }^{a}$ Faculty of Psychology and Educational Sciences, Babeş-Bolyai University, 7 Sindicatelor Street, 400015, Cluj-Napoca, Romania
}

*Corresponding author: delia.muste@ubbcluj.ro

\section{Abstract}

\section{Keywords:}

feedback; teaching; learning; academic performance
Feedback can be considered as the totality of information that is provided to the student, parent, or teacher regarding the student's performance, concerning learning objectives or learning outcomes and aims to improve learning among students. It has the role of reorienting the actions of the teacher, parent, or student in the direction of achieving specific goals of the learning process by aligning the effort and activity with a certain expected result. It can be offered about the results of the activity, the process itself, the way the student manages his learning or self-regulates in the learning activities. The power of feedback comes from the fact that he can straighten, maintain a good attitude, or change a student's behavior.

Giving direct but at the same time, empathetic feedback means allowing students to express their opinion, to give feedback in turn, to contradict you, or to recognize the problems when they arise. But all this requires tact, empathy, and understanding, because only in this way can we, the teachers, correct, direct and manage the challenges, in parallel with building communities in which students collaborate and care about each other. Feedback allows the other person to receive a real response to his action and is constructive when referring only to the action itself and nothing else.

\section{Zusammenfasung}

\section{Schlüsselworte:}

Feedback; Lehren;

Lernen;

Akademischeleistung
Feedback kann als die Gesamtheit der Informationen betrachtet werden, die dem Schüler, Elternteil oder Lehrer über die Leistung des Schülers in Bezug auf Lernziele oder Lernergebnisse zur Verfügung gestellt werden und die darauf abzielen, das Lernen unter den Schülern zu verbessern. Es hat die Aufgabe, die Handlungen des Lehrers, der Eltern oder des Schülers neu auszurichten, um bestimmte Ziele des Lernprozesses $z u$ erreichen, indem Aufwand und Aktivität auf ein bestimmtes erwartetes Ergebnis ausgerichtet werden. Es kann über die Ergebnisse der Aktivität, den Prozess selbst, die Art und Weise, wie der Schüler sein Lernen verwaltet oder sich in den Lernaktivitäten selbst reguliert, angeboten werden. Die Kraft des Feedbacks beruht auf der Tatsache, dass er sich aufrichten, eine gute Einstellung beibehalten oder das Verhalten eines Schülers ändern kann. Direktes, aber gleichzeitig einfühlsames Feedback zu geben bedeutet, den Schülern die Möglichkeit zu geben, ihre Meinung zu äußern, ihrerseits Feedback zu geben, Ihnen zu widersprechen oder die auftretenden Probleme zu erkennen. All dies erfordert jedoch Fingerspitzengefühl, Einfühlungsvermögen und Verständnis, denn nur so können wir als Lehrer die Herausforderungen korrigieren, lenken und bewältigen, parallel zum Aufbau von Gemeinschaften, in denen die Schüler zusammenarbeiten und sich umeinander kümmern. Feedback ermöglicht es der anderen Person, eine echte Antwort auf ihre Handlung zu erhalten, und ist konstruktiv, wenn sie sich nur auf die Handlung selbst und nichts anderes bezieht.

\section{Introduction}

Providing feedback on learning, often associated with the formative assessment process, has been shown to have positive influences on the school learning process and on the quality of student achievement (Richardson, 2005; Juwah et al, 2009; Black \& William, 1998). In fact, the importance of knowing and analyzing the mechanisms for providing feedback are already very well anchored in educational research focused on this topic. (Fisher \& Miller, 2008).

Feedback can also be defined as the totality of information that is provided to the student, parent or teacher regarding the student's performance, in relation to learning objectives or learning outcomes and aims to improve learning among students. It has the role of reorienting the actions of the teacher, parent or student towards achieving specific goals of the learning process by aligning effort and activity with a certain expected result and can be offered on the results of the activity, the process itself, the way in which the student manages his learning or self-regulates in the learning activities. Moreover, Avis (2010) indicates that the teacher's abilities to provide clear, constructive, supportive and delopmental feedback are part of their entire effective teaching process, as they consistently contribute to the identification by the instructor of the elements that are considered valuable in the teaching process.

Under these conditions, the teacher or parent can provide valuable corrective information, colleagues can provide alternative strategies, the book can provide 
information to clarify certain ideas, the parent can provide encouragement, and the student can analyze his response to assess the level of correctness. (https://brio.ro/adviser/feedback-ul/info/5, accessed on October 22, 2020)

When we talk about feedback, it is necessary to analyze two essential components: the transmitter and the receiver. The sender, in our case the person who provides feedback, must meet certain specific conditions: it must be defined correctly, used at the right time, in a certain context, to produce the desired effects. However, these conditions are not enough if the sender is not trained to receive and the receiver to use the feedback in a productive way. Thus, if the receiver listens, understands and accepts / assimilates the feedback, and then acts and obtains the desired results, only then can we discuss the existence of effective feedback.

If we analyze the importance of feedback, it is very important to analyze in depth the ways of manifestation, concretization, or realization within the daily instructiveeducational activity. In accordance with the typology of the feedback, over the years, attempts have been made to identify some hypostases under which it can materialize. In the interactional model proposed by De Landsheere and Bayer (1969), the functions assigned to the teacher are mentioned, among which we find them

- "positive feedback functions", in which the teacher may have behaviors such as

- approves it in a stereotypical manner;

- approves it by repeating the student's answer;

- approves it in a specific manner;

- approves it in another way;

- "negative feedback functions", which is in fact only the expression of a negative opinion about students' actions, without including useful recommendations for remedying the effects of those actions. Feedback of this type leads nowhere, but produces heated discussions or smoldering frustrations, especially from the one directly targeted by those remarks.In actions of this type, the teacher may manifest behaviors such as:

- disapproves in a stereotypical manner;

- disapproves by repeating the answer in an ironic or accusing manner;

- disapproves in a specific way;

- disapproves in another way;

- provides delayed feedback;

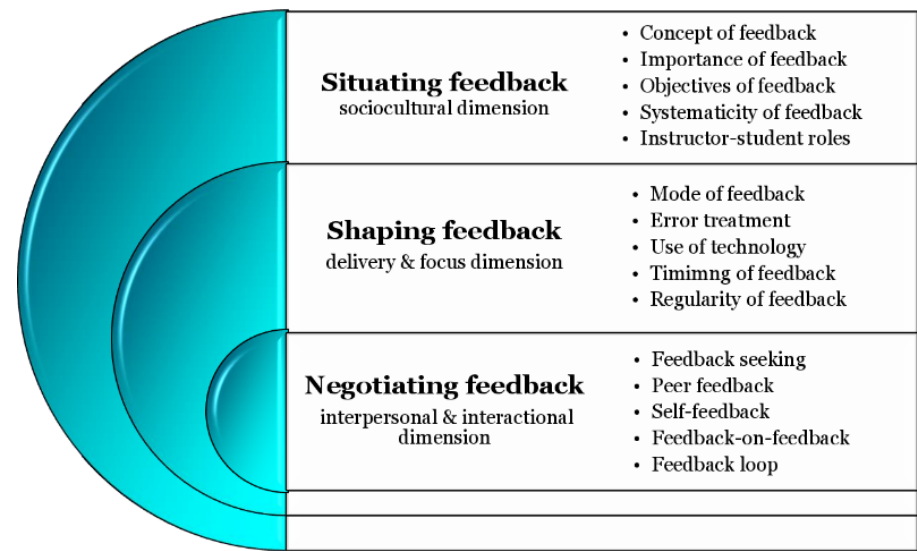

Figure 1. The feedback culture, a comparative exploration, Hisham M. Alfayyadh, 2016

(https://www.semanticscholar.org/paper/The-feedbackculture-in-translator-education\%3A-A-ofAlfayyadh/645e689fe95669d0ba0ad72b294501f60c6601f

\section{1)}

\section{Typology of school feedback}

In the educational reality we can identify 3 fundamental categories of feedback

\section{$>$ evaluative feedback (evaluates)}

- it can be positive or negative

- negative feedback will very rarely lead to the improvement of a behavior and also will not lead to maintaining the stability and balance of the learning act

- Positive feedback is a type of feedback that is very well received by students, often leading to improved behavior.

\section{$>$ prescriptive feedback (offers advice)}

- does not provide accurate information, rather focusing on what the subject should do, not on how he has already acted

- does not describe exactly what is happening, but what should happen

\section{$>$ descriptive feedback (describes authentic feedback)}

- it corresponds to the notion of authentic feedback

- it brings major improvements if offered correctly

- it generates remarkable results and reduces the defensive reaction of the students

The quality of descriptive feedback also depends on the teacher's knowledge about its specificity, so that it is made in accordance with the specific requirements for providing this type of feedback. The power of feedback comes from the fact that he can straighten, maintain a good mood, or change a student's behavior. Giving direct but at the same time empathetic feedback means giving students the opportunity to express their opinion, to give feedback in turn, to contradict you or to recognize the problems when they arise. But all this requires tact, empathy and understanding, because that is the only way we can correct, direct, and manage challenges, while building communities in which students collaborate and care about each other. Feedback allows the other person to receive a real response 
to his action and is constructive when referring only to the action itself and nothing else.

Thus, in the conditions of providing feedback to students, we consider the fact that this type of response is characterized by the fact that:

- Does not issue value judgments

- It is specific

- It is well targeted

- It is usually required

- It is well intentioned

- It is applicable

- It is realistic

- Brings improvements

Feedback studies show that it has a strong effect on learning, but it can nevertheless have a very wide range of effects, with the possibility, when not given properly, of producing negative effects. For this reason, it is important to have a good understanding of both the benefits and potential limits of feedback as an integral part of teaching and learning processes. In general, approaches that explicitly aim to provide feedback to students, such as Bloom's "performance-oriented learning", often have a positive impact. In fact, feedback has effects on all age groups. (Https://brio.ro/adviser/feedback-ul/info/5).

\section{Principles of formative feedback (Nicol \&} MacFarlane-Dick, 2009; Juwah et al, 2004)

1. Facilitates the development of self-assessment (reflection) in learning.

2. Encourage teacher and peer dialogue around learning.

3. Helps clarify what good performance is (goals, criteria, expected standards).

4. Provides opportunities to close the gap between current and desired performance.

5. Delivers high quality information to students about their learning.

6. Encourages positive motivational beliefs and selfesteem.

7. Provides information to teachers that can be used to help shape the teaching

Feedback should be tailored to the needs and preferences of each student. Some prefer private feedback because they may feel embarrassed if praised in front of others. Other children may respond better to feedback from others because they feel valued when their merits are recognized. Also, some children prefer verbal feedback, others prefer non-verbal feedback, therefore, depending on their age we can use gestures such as: clapping, applause, stickers, tickets, notes in a notebook for these actions, all serving as evidence of the child's progress, being able to view feedback whenever he needs to remember the path he had taken until then.

To be effective, however, feedback must occur in a learning context, as part of the teaching process, and must occur immediately after the student has provided an answer following the initial instruction, when the information is addressed. aspects related to the student's homework performance.

Hattie (2012) considers that in the teaching process it is necessary for the feedback to take into account 3 questions to which the student must answer, analyzing 4 levels of functioning. These three feedback questions are:

\section{What am I heading for? \\ How will I get there? \\ and}

\section{What's next?}

The four levels at which feedback works are: workload, methods used, self-regulation and self

1. Workload - in this context, feedback is effective if it is more focused on information (correct or incorrect), leads to the acquisition of more or more diverse information and builds more surface knowledge. This type of feedback is most common in the classroom and most students see feedback this way. It is often also called "corrective feedback" or "knowledge of results" and is usually given in class through teacher questions; it is given, most of the time, by the observations on the themes; it is often specific and cannot be generalized; is the most common type of feedback for the entire class.

2. At the level of the learning process - there is feedback regarding the methods used to obtain the result or complete the task. Such feedback can lead to providing alternative approaches, reducing cognitive loads, supporting the development of learning and error detection strategies, providing clues for a more effective search for information, recognizing the relationship between ideas.

3 . At the level of self-regulation - it is more focused on the register of self-regulation or on the monitoring by the student of his own learning process. Feedback at this level can improve students' self-assessment skills, provide greater confidence for further involvement in the task, support the student in requesting and accepting feedback, and increase their willingness to try to seek and use feedback.

4. At the level of the self - it is directed towards "self" (for example: "You are a good student!" Or "You did well!") And is usually associated with the notion of "praise". Praise is often used to provide peace and support; it is always present in many classes and is welcomed and expected by students, but often diverts attention from the task, method, or self-regulation. The main message is that you can give praise but be given in such a way as not to diminish the power of feedback.

Improper feedback can have severe repercussions on the educational act, with students being able to drop out of difficult tasks, which often leads to a lack of involvement in subsequent learning tasks. They can also "distort" the tasks, combining them with each other, choosing after their completion only the aspects that have been successfully completed and ignoring the failures. They can also lower 
their standards by choosing less challenging tasks, accepting as satisfactory a performance placed at a much lower level than their abilities would have allowed, just to avoid situations in which they are judged and criticized.

Training students' self-assessment skills is a systematic and complex process. To help teachers complete the selfassessment process, C. Rolheiser outlines four stages of student preparation, where feedback is highlighted throughout the process:

- Stage I - the teacher involves the students in determining the criteria. Often, students come up with ideas to negotiate with the teacher to reach the final criteria. In defining the criteria, it is important to use a language accessible to students.

- Stage II - the teacher demonstrates how the criteria are used in the evaluation of work tasks. Giving examples helps students understand the meaning of the criteria and how to apply them.

- Stage III - the teacher provides feedback on the application of the criteria, brings examples of different products that meet these criteria. The feedback will not focus on the correctness or incorrectness of the tasks, but how well the students applied the criteria, so it will refer to the evaluation criteria.

- Stage IV - involves identifying further learning objectives and strategies that can contribute to achieving them. In this context, students determine their own objectives and strategies, being directed by the teacher.

\section{Conclusions}

Feedback has both advantages and disadvantages. A major disadvantage for the teacher would be that it is time consuming. Thus, it is necessary for the teacher to take the time to find out what the students' level is, what their abilities and skills are, what the targeted performance is. And all this only at a stage preceding the moment when the feedback can be given. Also, creating the context in which the student feels safe when receiving feedback requires the allocation of a time frame that cannot be predicted exactly, due to human variables.

However, a major advantage of using feedback in the classroom is that using it regularly leads to effective learning, which can be noticed not only in terms of content, but also in terms of methods and techniques.

It is important to always remember that the learning process is a complex one, sometimes difficult, both for parents, teachers, but especially for children. Effective communication is the path to success, so it is necessary to communicate coherently and constantly, to always express our expectations patiently and calmly, to be firm but also understanding and always open to new ways of achieving goals. Each child has his own learning style, but with perseverance we can make the learning experience a positive experience, full of satisfaction and remarkable results.

\section{Authors note:}

Delia Muste has a $\mathrm{PhD}$ in education sciences and is a lecturer at the Department of Education Sciences, Faculty of Psychology and Education Sciences, Babeș-Bolyai University Cluj-Napoca, Romania. Her areas of interest and research cover several domains (including interdisciplinary ones), such as the educational communication, educational alternatives, civic education, time management applied in education and teacher training programme.

\section{References}

Alfayyadh, H. (2016). The feedback culture in translator education: A comparative exploration of two distinct university translation programs, accessed in 20 october 2020, Available at https://www.semanticscholar.org/paper/Thefeedback-culture-in-translator-education $\% 3 \mathrm{~A}$-A-ofAlfayyadh/645e689fe95669d0ba0ad72b294501f60c6 601f1.

Avis, J., Fisher, R., Thompson, R. (2010). Teaching in lifelong learning: A guide to theory and practice. Maidenhead: Open University Press.

Black, P., Wiliam, D., 1998. Assessment and classroom learning. Assessment in Education: principles, policy \& practice, 5(1), 7-74. Routledge, London.

Brookhart, S. M. (2008). How to give effective feedback to your students. Virginia: Association for Supervision \& Curriculum Development.

De Landsheere, G., Bayer, E. (1969) Comment les maîtres enseignent. Analyse des interactions verballes en classe, Bruxelles, Ministère de l'Education Nationale et de la Culture.

Fisher, R., and Miller, D., 2008. Responding to student expectations: A partnership approach to course evaluation. Assessment \& Evaluation in Higher Education, 33(2), 191-202. Taylor\&Francis online, Available https://doi.org/10.1080/02602930701292514 (Accessed at 21.10. 2020).

Hattie, J., Timperley H (2007) The Power of Feedback, Review of Educational Research March 2007, Vol. 77, No. 1, pp. 81-112 DOI: 10.3102/003465430298487; Available http://www.columbia.edu/ mvp19/ETF/Feedback.pdf (Accessed at.20.102020).

Hattie, J. (2012). Visible learning for teachers: Maximizing impact on learning. London: Routledge.

Juwah, C., Macfarlane-Dick, B., Matthew, D., Nicol, D., and Smith, B., (2009). Enhancing Student Learning Through Effective Formative Feedback. York. The Higher Education Academy (Generic Centre).

Nicol, D., MacFarlane-Dick, D., (2009) Rethinking Formative Assessment in HE: a theoretical model and seven principles of good feedback practice.Available 
at

https://www.researchgate.net/publication/251777530 _Rethinking_Formative_Assessment_in_HE_a_theor etical_model_and_seven_principles_of_good_feedba ck_practice.

Pullen, Darren \& Collette, Steven \& Dao, Loan \& F, J. (2019). Student Evaluations of Teaching: Is There a Relationship between Student Feedback on Teaching and the Student Final Grade? Available at Frontiers in Education Technology. 2,p. 124. 10.22158/fet.v2n3p124.
Richardson, J. (2005). Instruments for obtaining student feedback: A review of the literature. Assessment and Evaluation in Higher Education, 30, 387-415. Available at https://doi.org/10.1080/02602930500099193.

Rolheiser, C. (1996) Self-Evaluation helping Students Get better at It! A Teacher's Resource book. Toronto: Cooperative learning Evaluation \& Assessment Research Group.

*** https://brio.ro/adviser/feedback-ul/info/5 (Accessed at 20.10.2020). 